\title{
Multiplexed analysis combining distinctly-sized CdTe-MPA quantum dots and chemometrics for multiple mutually interfering analyte determination
}

\author{
Dayana B. Bittar ${ }^{\mathrm{a}}$, David S.M. Ribeiro ${ }^{\mathrm{b}, *}$, Ricardo N.M.J. Páscoa ${ }^{\mathrm{b}}$, José X. Soares $^{\mathrm{b}}$, S. Sofia \\ M. Rodrigues ${ }^{\mathrm{b}}$, Rafael C. Castro ${ }^{\mathrm{b}}$, Leonardo Pezza ${ }^{\mathrm{a}}$, Helena R. Pezza ${ }^{\mathrm{a}}$, João L.M. Santos ${ }^{\mathrm{b}, *}$ \\ a Instituto de Química, Universidade Estadual Paulista "Júlio de Mesquita Filho", UNESP, R. Prof. Francisco Degni 55, P.O. Box 355, 14800-900 Araraquara, \\ $S P$, Brazil \\ ${ }^{\mathrm{b}}$ LAQV, REQUIMTE, Department of Chemical Sciences, Laboratory of Applied Chemistry, Faculty of Pharmacy, University of Porto, Rua de Jorge Viterbo \\ Ferreira no 228, 4050-313 Porto, Portugal
}

\section{A R T I C L E I N F O}

\section{Keywords:}

CdTe quantum dots

Heavy metals

Multiplexing

Chemometrics

Fluorescence

Multiparametric analysis

\begin{abstract}
A B S T R A C T
Semiconductor quantum dots (QDs) have demonstrated a great potential as fluorescent probes for heavy metals monitoring. However, their great reactivity, whose tunability could be difficult to attain, could impair selectivity yielding analytical results with poor accuracy. In this work, the combination in the same analysis of multiple QDs, each with a particular ability to interact with the analyte, assured a multi-point detection that was not only exploited for a more precise analyte discrimination but also for the simultaneous discrimination of multiple mutually interfering species, in the same sample. Three different MPA-CdTe QDs (2.5, 3.0 and $3.8 \mathrm{~nm})$ with a good size distribution, confirmed by the FWHM values of 48.6, 55.4 and $80.8 \mathrm{~nm}$, respectively, were used. Principal component analysis (PCA) and partial least squares regression (PLS) were used for fluorescence data analysis. Mixtures of two MPA-CdTe QDs, emitting at different wavelength namely 549/566, 549/634 and 566/ $634 \mathrm{~nm}$ were assayed. The 549/634 nm emitting QDs mixture provided the best results for the discrimination of distinct ions on binary and ternary mixtures. The obtained RMSECV and $\mathrm{R}^{2} \mathrm{CV}$ values for the binary mixture were good, namely, from 0.01 to $0.08 \mathrm{mg} \mathrm{L}^{-1}$ and from 0.74 to 0.89 , respectively. Regarding the ternary mixture the RMSECV and $\mathrm{R}^{2} \mathrm{CV}$ values were good for $\mathrm{Hg}$ (II) (0.06 and $0.73 \mathrm{mg} \mathrm{L}^{-1}$, respectively) and $\mathrm{Pb}$ (II) (0.08 and $0.87 \mathrm{mg} \mathrm{L}^{-1}$, respectively) and acceptable for $\mathrm{Cu}(\mathrm{II})\left(0.02\right.$ and $0.51 \mathrm{mg} \mathrm{L}^{-1}$, respectively). In conclusion, the obtained results showed that the developed approach is capable of resolve binary and ternary mixtures of $\mathrm{Pb}$ (II), $\mathrm{Hg}$ (II) and $\mathrm{Cu}$ (II), providing accurate information about lead (II) and mercury (II) concentration and signaling the occurrence of $\mathrm{Cu}$ (II).
\end{abstract}

\section{Introduction}

One of the most challenging fields of nanotechnology contemplates the development of nanomaterials to be applied as efficient and reliable (bio)chemosensors for a multiplicity of organic and inorganic species in distinct analytical endeavors [1]. Quantum dots (QDs) are a class of nanoparticles that besides the features associated with their small size, such as high surface-to-volume ratio and reactivity, they also exhibit remarkable properties that outshine those of conventional materials. Among these, the high size-tunable photoluminescence (PL) and longterm photostability, broad excitation and narrow emission spectra, and the great operational and instrumental simplicity associated with their utilization with analytical purposes, should be highlighted [2].

On the opposite side, when devoid of specific analyte recognition mechanisms, QDs proneness to participate in a variety of reactional schemes limits their applicability when the sample matrix is complex and/or interfering species are present. In this context QDs are capable of assuring sensitivity, high sample throughput and broad analytical concentration working ranges, but selectivity is usually severely restrained. Basically, their photoluminescence could be modulated by a variety of factors, including $\mathrm{pH}$, ionic strength, the presence of adsorbates and chelating molecules, the occurrence of oxidizing or reducing agents, heavy metals, etc, not directly related with the specie under analysis. These are capable of interacting with the QDs affecting the measured PL either in terms of intensity, emission maxima or lifetime. QDs selectivity could be more or less amended by using specific capping ligands more likely to interact with the analyte, by adjustment of QDs size, by using dopants or by exploring indirect measurements relying on competing molecules, etc. Nonetheless, the success of these measures is usually limited, in particular in the case of

\footnotetext{
* Corresponding authors.

E-mail addresses: dsmribeiro@gmail.com (D.S.M. Ribeiro), joaolms@ff.up.pt (J.L.M. Santos).
} 
typical QD-based (bio)chemosensors relying on the monitoring of a single interaction between the analyte and the probe.

An expeditious strategy to overcome this limitation involves the simultaneous utilization of multiple QDs, with distinct properties and reactivity and capable of establishing multiple variable magnitude interactions with the analyte. This is achieved by combining, in the same analysis, several QDs with dissimilar composition and size, emitting at distinct wavelength and with varied surface ligands, thus enabling a multi-wavelength detection of all analyte-triggered changes on the QDs photoluminescence. Although all QDs might react with the analyte, the combination of the individual responses gives rise to a multi-point detection which could provide additional and more reliable information concerning the analyte occurrence. Moreover, if the QDs interaction are adequately discriminate, and by using chemometrics for data processing and analysis, it would be possible to simultaneously analyze more than one analyte with the same set of QDs.

In this work we have studied how the combination of QDs with distinct reactivity, which resulted merely from distinct size, could be exploited for multi-analyte monitoring. Cadmium telluride (CdTe) QDs were used due to the great simplicity of preparation by hydrothermal method [3], which allowed the obtaining of nanocrystals with narrow size distribution, narrow and symmetric emission spectra, high quantum yield and long-term water stability. Moreover, in recent years CdTe QDs have been extensively used in chemical analysis confirming to be excellent fluorescent probes for the monitoring of a wide variety of species [4-10]. The CdTe QDs were synthesized by using a short chain thiol molecule, 3-mercaptopropionic acid (MPA), as capping ligand and distinct heating times in order to attain sizes ranging from 2.48 to $3.81 \mathrm{~nm}$.

As target analytes three distinct heavy metals $\mathrm{Hg}(\mathrm{II}), \mathrm{Cu}(\mathrm{II})$ and $\mathrm{Pb}$ (II) were assayed. Mercuric ion $\left(\mathrm{Hg}^{2+}\right)$ is one of the most hazardous heavy metals in the environment. Due to its high bioavailability through biological membranes it could cause serious damage to the central nervous and endocrine systems [11]. Copper is an essential element for many living organisms, but it becomes toxic at high concentrations [12]. $\mathrm{Pb}^{2+}$ has received a great attention as a consequence of the adverse environmental and health problems resulting from lead poisoning [13].

Many works have demonstrated that these heavy metals showed a great reactivity towards CdTe QDs, yielding pronounced PL quenching effects, and acting as interfering species among each other in individual assays $[14,15]$. In this work, distinct combinations of the referred heavy metals at low level concentrations were assayed, in two or three components sets, confirming that the developed approach was capable of satisfactorily discriminate the occurring species and the respective concentration.

\section{Experimental}

\subsection{Reagents and solutions}

Chemicals used in this work were all of analytical reagent grade without any treatment process. All solutions and standards were prepared using water purified from a Milli-Q system (conductivity $\leq$ $0.1 \mu \mathrm{S} \mathrm{cm}^{-1}$ ).

The reagents for the synthesis of the CdTe QDs, namely, cadmium chloride hemi(pentahydrate) $\left(\mathrm{CdCl}_{2} \cdot 2.5 \mathrm{H}_{2} \mathrm{O}, 99 \%\right)$, sodium tellurite $\left(\mathrm{Na}_{2} \mathrm{TeO}_{3}, 100\right.$ mesh, 99\%), sodium borohydride $\left(\mathrm{NaBH}_{4}, 99 \%\right), 3-$ mercaptopropionic acid (MPA, 99\%) and sodium citrate tribasic dehydrate $\left(\mathrm{C}_{6} \mathrm{H}_{5} \mathrm{Na}_{3} \mathrm{O}_{7} \cdot 2 \mathrm{H}_{2} \mathrm{O}, 99 \%\right)$ were all purchased from SigmaAldrich (St. Louis, MO, USA) and used without further treatment. Sodium hydroxide $(\mathrm{NaOH}, 98 \%)$ was purchased from Panreac (Barcelona, Spain).

To adjust $\mathrm{pH}$ a $\mathrm{NaOH}$ solution $1.0 \mathrm{~mol} \mathrm{~L}^{-1}$ was used. QDs were used as prepared only by appropriate dilutions of crude solutions without any purification process.
Copper, lead and mercury intermediate solutions of $10 \mathrm{mg} \mathrm{L}^{-1}$ were prepared by proper dilutions from their stock standard solutions (Merck ${ }^{\circledR}$, Darmstadt, Germany) with concentration of $1000 \mathrm{mg} \mathrm{L}^{-1}$.

\subsection{Apparatus}

The synthesis of quantum dots was performed in a CEM Discover $\mathrm{SP}^{\circ}$ Microwave Synthesizer which was operated by a computer using Synergy $^{\mathrm{TM}}$ software (Matthews, NC, US). The microwave was equipped with an integrated infrared (IR) sensor, an automated pressure control/sensing system (ActiVent ${ }^{\mathrm{TM}}$ ) and an active cooling system $\left(\right.$ PowerMAX $\left.{ }^{\mathrm{TM}}\right)$. QDs absorption and emission spectra were obtained by using a Jasco V-660 spectrophotometer and a Jasco FP-6500 spectrofluorometer (Easton, MD, USA), respectively. The quantum yield (QY) at room temperature was measured using a QuantaurusQY Absolute PL Quantum Yield Spectrometer C11347-11 (Hamamatsu, Japan) equipped with an integration sphere and a $150 \mathrm{~W}$ xenon light source. The $\mathrm{pH}$ measurements were made with a pH-meter GLP 22 (CRISON).

\subsection{Synthesis of MPA capped CdTe QDs assisted by microwave irradiation}

Three different diameters of MPA capped CdTe QDs were synthesized by resorting to the one-pot MW-assisted aqueous synthetic route as proposed by Ribeiro et al. [16]. Briefly, an equimolar quantity of $\mathrm{CdCl}_{2}$ and MPA $\left(1.25 \times 10^{-3} \mathrm{~mol}\right)$ was mixed in $125 \mathrm{~mL}$ of deionized water. The resultant mixture were then added to a second beaker where $2.5 \times 10^{-4} \mathrm{~mol}$ of $\mathrm{Na}_{2} \mathrm{TeO}_{3}, 4 \times 10^{-3} \mathrm{~mol}$ of $\mathrm{NaBH}_{4}$, and $1.25 \times$ $10^{-3} \mathrm{~mol}$ of citrate were separately placed. The $\mathrm{pH}$ of the final solution was adjusted to 11 with a $1.0 \mathrm{~mol} \mathrm{~L}^{-1} \mathrm{NaOH}$ solution. So, the molar ratio of Cd:Te:MPA was fixed at 1.0:0.2:1.0. By fixing the MW irradiation time at $10 \mathrm{~min}$, the size of CdTe QDs was tuned by changing the temperature namely, 95, 105 and $125^{\circ} \mathrm{C}$.

The QDs were used in the assays as prepared without any purification treatment because the high level dilutions (of the original colloidal solution) that was employed during the analyses were enough to guarantee the minimization of potential interferents.

\subsection{Procedure for the fluorometric measurements}

The combined CdTe QDs fluorometric probe for the detection of different metals ions consisted in a mixture of two different sized MPAcapped CdTe QDs. Thus, into a $2 \mathrm{~mL}$ Eppendorf tube, $1200 \mu \mathrm{L}$ of a green emitting QDs $(549 \mathrm{~nm})$ and $800 \mu \mathrm{L}$ of a red emitting QDs $(634 \mathrm{~nm})$ were mixed originating a fluorometric probe with two welldefined emission peaks.

Subsequently, into different Eppendorf tubes, $10 \mu \mathrm{L}$ of the fluorometric probe and required amounts of metal ion, individually or in mixture, were sequentially added and the final volume $(2 \mathrm{~mL})$ was completed with deionized water. Immediately after mixing, the solution was transferred into a $1 \mathrm{~cm}$ quartz cell and the emission spectra (490$740 \mathrm{~nm}$ ) were recorded with the excitation wavelength fixed at $400 \mathrm{~nm}$. The slit widths of excitation and emission were $5.0 \mathrm{~nm}$.

\subsection{Experimental design}

The concentration of the mixtures prepared with two and three metal ions (Table 1) was established according to an experimental design. For the mixtures containing two metal ions, six levels plus 3 additional center points were used, in a total of 39 experiments. The used concentration levels were: $0.01,0.03,0.04,0.05,0.06$ and $0.08 \mathrm{mg} \mathrm{L}^{-1}$ for $\mathrm{Cu}(\mathrm{II})$; $0.1,0.15,0.2,0.3,0.35$ and $0.4 \mathrm{mg} \mathrm{L}^{-1}$ for $\mathrm{Hg}(\mathrm{II}) ; 0.05,0.2,0.3,0.4,0.5$ and $0.6 \mathrm{mg} \mathrm{L}^{-1}$ for $\mathrm{Pb}(\mathrm{II})$. Regarding the mixture containing three metal ions, four levels plus 3 additional center points were used, making a total of 67 experiments. Consequently, two 
Table 1

Concentrations of the metal ions used in the mixtures.

\begin{tabular}{|c|c|c|c|}
\hline & \multicolumn{3}{|l|}{ Concentrations $\left(\mathrm{mg} \mathrm{L}^{-1}\right)$} \\
\hline & Mixture of two metal ions & $\begin{array}{l}\text { Mixture of three metal } \\
\text { ions }\end{array}$ & Center points \\
\hline $\mathrm{Cu}(\mathrm{II})$ & $\begin{array}{l}0.01 ; 0.03 ; 0.04 ; 0.05 ; 0.06 ; \\
0.08\end{array}$ & $0.01 ; 0.03 ; 0.05 ; 0.08$ & 0.045 \\
\hline $\mathrm{Hg}(\mathrm{II})$ & $0.1 ; 0.15 ; 0.2 ; 0.3 ; 0.35 ; 0.4$ & $0.1 ; 0.2 ; 0.3 ; 0.4$ & 0.25 \\
\hline $\mathrm{Pb}(\mathrm{II})$ & $0.05 ; 0.2 ; 0.3 ; 0.4 ; 0.5 ; 0.6$ & $0.05 ; 0.2 ; 0.4 ; 0.6$ & 0.325 \\
\hline
\end{tabular}

concentration levels of each metal ion were not prepared. The solutions containing $0.04,0.06 \mathrm{mg} \mathrm{L}^{-1}$ of $\mathrm{Cu}(\mathrm{II}), 0.15,0.35 \mathrm{mg} \mathrm{L}^{-1}$ of $\mathrm{Hg}(\mathrm{II})$ and $0.3,0.5 \mathrm{mg} \mathrm{L}^{-1}$ of $\mathrm{Pb}$ (II) were not used. The center points used for $\mathrm{Cu}(\mathrm{II}), \mathrm{Hg}$ (II) and $\mathrm{Pb}(\mathrm{II})$ were $0.045,0.25$ and $0.325 \mathrm{mg} \mathrm{L}^{-1}$.

\subsection{Data analysis}

The fluorescence data were analyzed through principal component analysis (PCA) [17] and partial least squares regression (PLS) [18]. The PCA was used for outlier's detection through the analysis of Hotelling's T2 and squared residuals statistics [17]. PLS-1 algorithm was used to obtain a multivariate calibration for each analyte $\mathrm{Pb}(\mathrm{II}), \mathrm{Hg}(\mathrm{II}), \mathrm{Cu}(\mathrm{II})$, individually [18]. All the PLS models were optimized in terms of the best number of latent variables, by using the leave-one-out procedure cross validation method, to prevent model over-fitting and to ensure robustness. The best number of latent variables was chosen through a commitment between the lowest root mean square error of crossvalidation (RMSECV) and the lowest number of latent variables (LV). The root mean square error of calibration and cross-validation (RMSEC and RMSECV, respectively) were calculated according to the following equation:

$R M S E=\sqrt{\frac{\sum_{i=1}^{N}\left(\hat{y}_{i}-y_{i}\right)^{2}}{N}}$

In Eq. (1), $\mathrm{N}$ is the number of samples, $y_{i}$ is the experimental result for sample $i$ and $\hat{y_{i}}$ is the value obtained for the calibration set (RMSEC) and the cross-validation (RMSECV). The Pearson's correlation coefficient was also calculated to compare experimental values with the estimations for the prediction set.

To assess the models predictive capacity the RMSECV and the coefficient of determination of cross-validation $\left(\mathrm{R}_{\mathrm{CV}}^{2}\right)$ were used.

All calculations were carried out using Matlab version R2009b (MathWorks, Natick, MA, USA) and the PLS Toolbox version 5.5.1 (Eigenvector Research, Inc., WA, USA).

\section{Results and discussion}

\subsection{Characterization of the as-prepared CdTe QDs capped with MPA}

The characterization of the different sized MPA-capped CdTe QDs in terms of optical properties was performed by absorption and fluorescent spectroscopy (Fig. 1). The obtained results are presented in Table 2 and include the wavelengths of maximum absorbance corresponding to the first excitonic transition, wavelengths of maximum emission, Full Width at Half Maximum values of the emission peak (FWHM) and the corresponding sizes and molar concentrations.

The size of the nanoparticles (D) was determined taking into account the obtained wavelengths of maximum absorption $(\lambda)$ using the equation proposed by $\mathrm{Yu}$ et al. [19]:

$\mathrm{D}=(9.8127 .10 .7) \lambda^{3}-(1.7147 .10 .3) \lambda^{2}+(1.0064) \lambda-194.84$.

Based on the value of $\mathrm{D}$, the molar absorptivity $(\varepsilon)$ was determined through the equation $\varepsilon=3450 \times \Delta \mathrm{E} \times(\mathrm{D})^{2.4}$, where $\Delta \mathrm{E}$ represents the transition energy corresponding to the first absorption peak expressed in eV. The molar concentration (C) expressed in $\mathrm{mol} \mathrm{L}^{-1}$ is then calculated using the Lambert-Beer law [19].

The three different sized QDs exhibited wide absorption bands with well-defined absorption maxima for the first excitonic transition and narrow and symmetric emission bands, evidencing adequate nanoparticles monodispersity and homogeneity. However, it is important to mention that the FWHM increases with increasing MW synthesis temperatures and consequently the size uniformity decreases. The excessive temperatures can lead to a broad size distribution which impairs the QDs spectral properties.

Additionally, according to the results shown in Table 2, by raising the temperature from 95 to 125, the wavelength of maximum absorbance corresponding to the first excitonic transition, the wavelength of maximum emission and the corresponding nanoparticles sizes also increased. The obtained results are in agreement with those obtained by Ribeiro et al. [16] thus confirming that by fixing the time of synthesis, the temperature increment promotes an increasing growth rate. Additionally, the quantum yields (QY) of the nanoparticles synthesized at 95,105 and $125^{\circ} \mathrm{C}$ were $13.3 \%, 27.2 \%$ and $63.6 \%$, respectively. This QY enhancement is attributed to the improvement of QDs crystallinity and surface passivation.

In this work two different sized MPA-capped CdTe QDs were conjugated in a nanohybrid 549/634 nm MPA-capped CdTe QDs system to be used as fluorometric probe for the detection and differentiation of distinct ions. The green and red emitting MPACdTe QDs were mixed in a proportion of 60:40, respectively, originating a combined CdTe QDs fluorometric probe with two well-defined emission peaks as shown in Fig. 2. The two wavelengths of maximum emission were 549 and $634 \mathrm{~nm}$ and the QY of the resultant fluorometric probe was about $60 \%$.

\subsection{Preliminary assays}

The PL properties of MPA-CdTe QDs with different sizes (2.48, 3.03 and $3.81 \mathrm{~nm}$ ) were assessed upon the interaction with three different metal ions, $\mathrm{Cu}$ (II), $\mathrm{Pb}$ (II) and $\mathrm{Hg}$ (II), at different concentration ranges. For each size of QDs, these concentration ranges were of 0-0.7, $0-2.0$ and $0-1.5 \mathrm{mg} \mathrm{L}^{-1}$ for $\mathrm{Cu}$ (II), $\mathrm{Pb}$ (II) and $\mathrm{Hg}$ (II), respectively. The QDs concentrations used in these assays were $1.5 \times 10^{-2}, 3.5 \times$ $10^{-3}, 1.8 \times 10^{-3} \mu \mathrm{mol} \mathrm{L}^{-1}$ for nanoparticle size of $2.48,3.03$ and $3.81 \mathrm{~nm}$, respectively. Using these conditions, the fluorescence intensity of each QDs size in the absence of the metal ion was similar.

The obtained results demonstrated that for all the synthesized QDs sizes the fluorescence intensity decreased by adding increasing concentrations of each of the assessed metal ions. Along with the PL quenching both $\mathrm{Pb}$ (II) and $\mathrm{Hg}$ (II) ions caused a redshift of the wavelength of maximum emission in all QDs sizes, a phenomenon that not occurred in the case of the QDs interaction with $\mathrm{Cu}$ (II) ions.

According to the literature [10], the PL quenching of CdTe QDs upon the interaction with $\mathrm{Pb}(\mathrm{II}), \mathrm{Hg}$ (II) and $\mathrm{Cu}(\mathrm{II})$ is ascribed to effective electron transfer between donor and acceptor sites of the fluorophore/quencher system which induce the disruption of radiative electron-hole recombination. The observed red-shift caused by $\mathrm{Pb}(\mathrm{II})$ and $\mathrm{Hg}(\mathrm{II})$ was also reported in literature [20], and was attributed to the formation of new radiative centers.

Under an analytical perspective, the detection, quantification and discrimination of $\mathrm{Hg}(\mathrm{II}), \mathrm{Pb}(\mathrm{II})$ and $\mathrm{Cu}(\mathrm{II})$ ions in the same sample, based simply on their quenching effect on a single quantum dot PL is impracticable, due to the occurrence of interfering effects among each other. Nevertheless, each metal ion/QDs interaction has a specific magnitude that depends on many aspects, namely on the ion concentration and QDs size. Consequently, if any of the referred heavy metals is made to react with a mixture of MPA-CdTe QDs of different sizes, and emitting at complementary wavelengths, it would yield a distinctive emission spectrum profile that would combine all QDs responses. If the different emission spectra profiles are processed by multivariate 


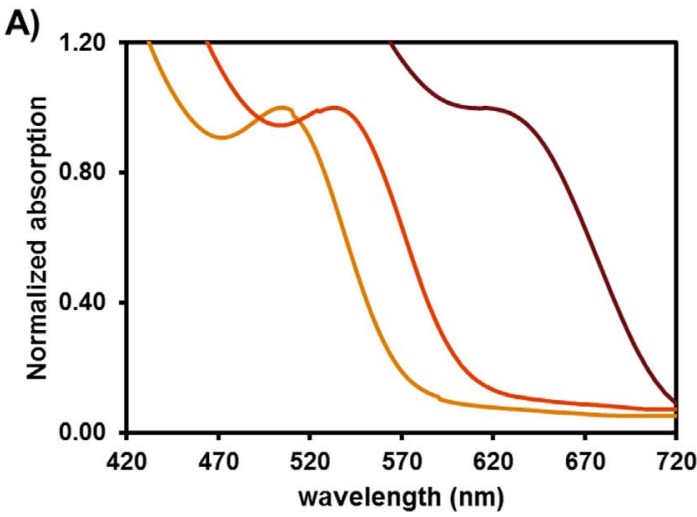

B)

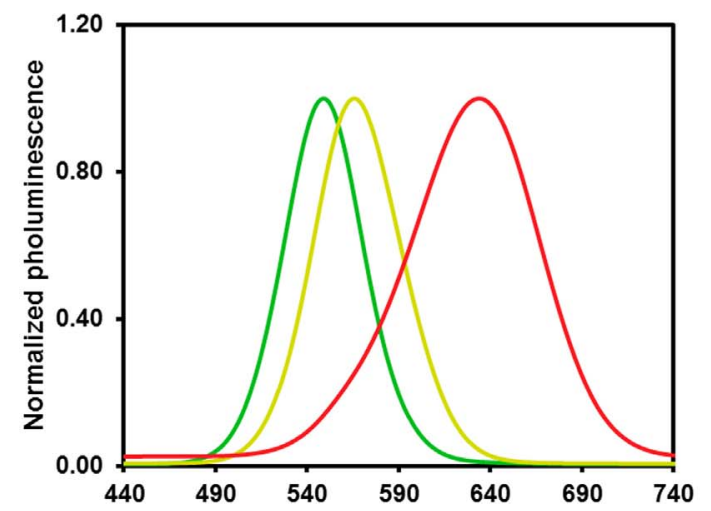

C)

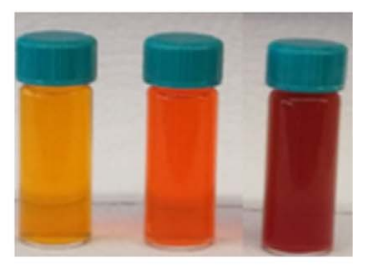

D)

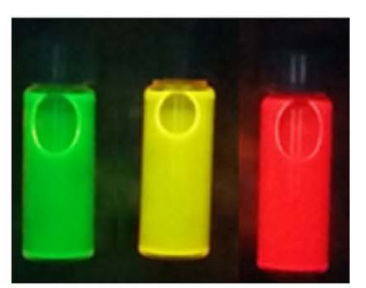

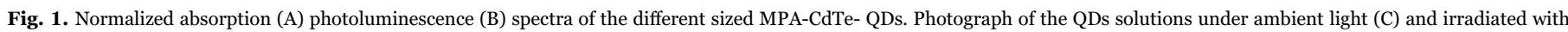
UV light at $365 \mathrm{~nm}$ (D).

Table 2

CdTe-MPA QDs characterization.

\begin{tabular}{llll}
\hline Temperature & $95^{\circ} \mathrm{C}$ & $105^{\circ} \mathrm{C}$ & $125^{\circ} \mathrm{C}$ \\
\hline$\lambda$ Absorption (nm) & 505 & 533 & 615 \\
$\lambda$ Emission (nm) & 549 & 566 & 634 \\
FWHM & 48.56 & 55.39 & 80.82 \\
D (nm) & 2.48 & 3.03 & 3.81 \\
$\mathrm{C}\left(\mathrm{mol} \mathrm{L}^{-1}\right)$ & $5.11 \times 10^{-6}$ & $1.38 \times 10^{-6}$ & $8.90 \times 10^{-7}$ \\
\hline
\end{tabular}

chemometrics methods, they could provide both the discrimination of each individual metal ion and of the whole mixtures of ions.

Mixtures of two MPA-CdTe QDs, with different $\lambda_{\text {em }}$, namely $549 /$ $566,549 / 634$ and $566 / 634 \mathrm{~nm}$ were prepared and tested as fluorometric probes for $\mathrm{Hg}$ (II), $\mathrm{Pb}$ (II) and $\mathrm{Cu}(\mathrm{II})$ determination. Among the studied combinations the $549 / 634 \mathrm{~nm}$ arrangement demonstrated to be the most effective for the evaluated metal ions. In effect, along with the high sensitivity demonstrated for each of the ions, the emission spectrum of the $549 / 634 \mathrm{~nm}$ mixture presented two well-defined bands which allowed improved resolution in the discrimination of the occurring ions.

The stability of the PL intensity of the 549/634 nm MPA-CdTe QDs was evaluated every day by approximately forty days. The obtained results revealed that PL intensity remains constant for approximately 1 month demonstrating the high stability of the $549 / 634 \mathrm{~nm}$ system as fluorometric probe.

\subsection{Interaction between the 549/634 nm MPA-CdTe QDs fluorometric probe and $\mathrm{Hg}(\mathrm{II}), \mathrm{Pb}(\mathrm{II})$ and $\mathrm{Cu}(\mathrm{II})$, individually}

The PL response of the $549 / 634 \mathrm{~nm}$ probe was evaluated upon interaction with $\mathrm{Cu}$ (II), $\mathrm{Pb}$ (II) and $\mathrm{Hg}$ (II) at a concentration range of
$0-0.7,0-2.0$ and $0-1.5 \mathrm{mg} \mathrm{L}^{-1}$, respectively. The emission spectra of all solutions were recorded from 490 to $740 \mathrm{~nm}\left(\lambda_{\mathrm{ex}}=400 \mathrm{~nm}\right)$. The obtained results depicted in Fig. 3 showed that, although all metals caused a PL quenching, the reactivity of the probe towards $\mathrm{Cu}$ (II), $\mathrm{Pb}$ (II) and $\mathrm{Hg}(\mathrm{II})$ ions is very distinctive. In the case of $\mathrm{Hg}(\mathrm{II})$ (Fig. 3C)), a more pronounced PL inhibition was observed at the $549 \mathrm{~nm}$ band for concentrations up to $0.6 \mathrm{mg} \mathrm{L}^{-1}$, which was also accompanied by a red-shift of $10 \mathrm{~nm}$ (from 549 to $559 \mathrm{~nm}$ ). For higher concentrations it was also observed a PL quenching at the $634 \mathrm{~nm}$ band accompanied by a red-shift of $29 \mathrm{~nm}$ (from 634 to $663 \mathrm{~nm}$ ). With this QDs combination the $\mathrm{Hg}$ (II) ions revealed a higher affinity for the smaller QDs relatively to the bigger ones.

Concerning the interaction with $\mathrm{Pb}(\mathrm{II}$ ) ions (Fig. 3B)), a higher affinity for the smaller QDs was also verified but this was much less pronounced than the one noticed with $\mathrm{Hg}$ (II). It was as well observed a red-shift of $5 \mathrm{~nm}$ of the $549 \mathrm{~nm}$ maximum, for $\mathrm{Pb}(\mathrm{II})$ concentration up to $0.800 \mathrm{mg} \mathrm{L}^{-1}$. The $634 \mathrm{~nm}$ emission band exhibited a red shift of $32 \mathrm{~nm}$ (to $666 \mathrm{~nm}$ ).

These results confirmed that the size of QDs can modulate the electron transfer efficiency, as described by Zhong et al. [20]. The highest affinity of the metal ions towards the smaller QDs was attributed to the fact that the quencher can reach the nanoparticle core whilst for the larger ones the interaction with the excitons is restrained at the surface.

Finally, concerning the interaction of the fluorometric probe with $\mathrm{Cu}(\mathrm{II})$ ions (Fig. 3A)), the PL inhibition observed for both 549 and $634 \mathrm{~nm}$ emission bands was similar indicating that the affinity of $\mathrm{Cu}$ (II) in relation to the two different sized QDs was analogous, in contrast to what was verified with $\mathrm{Pb}$ and $\mathrm{Hg}$ ions. In addition, no significant shift of the wavelength of maximum emission was observed in both 549 and $634 \mathrm{~nm}$ bands.

As the fluorometric probe consisted in a mixture of two different 


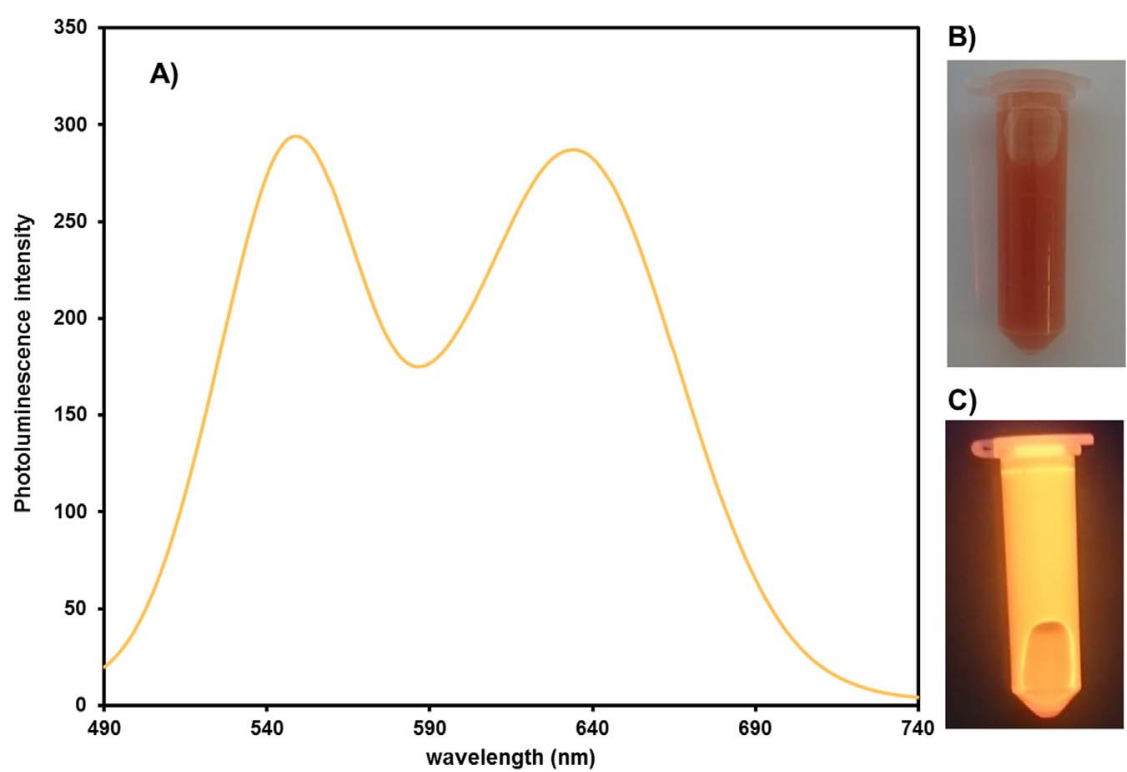

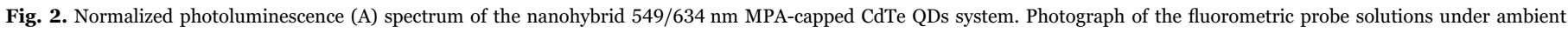
light (B) and irradiated with UV light at $365 \mathrm{~nm}$ (C).
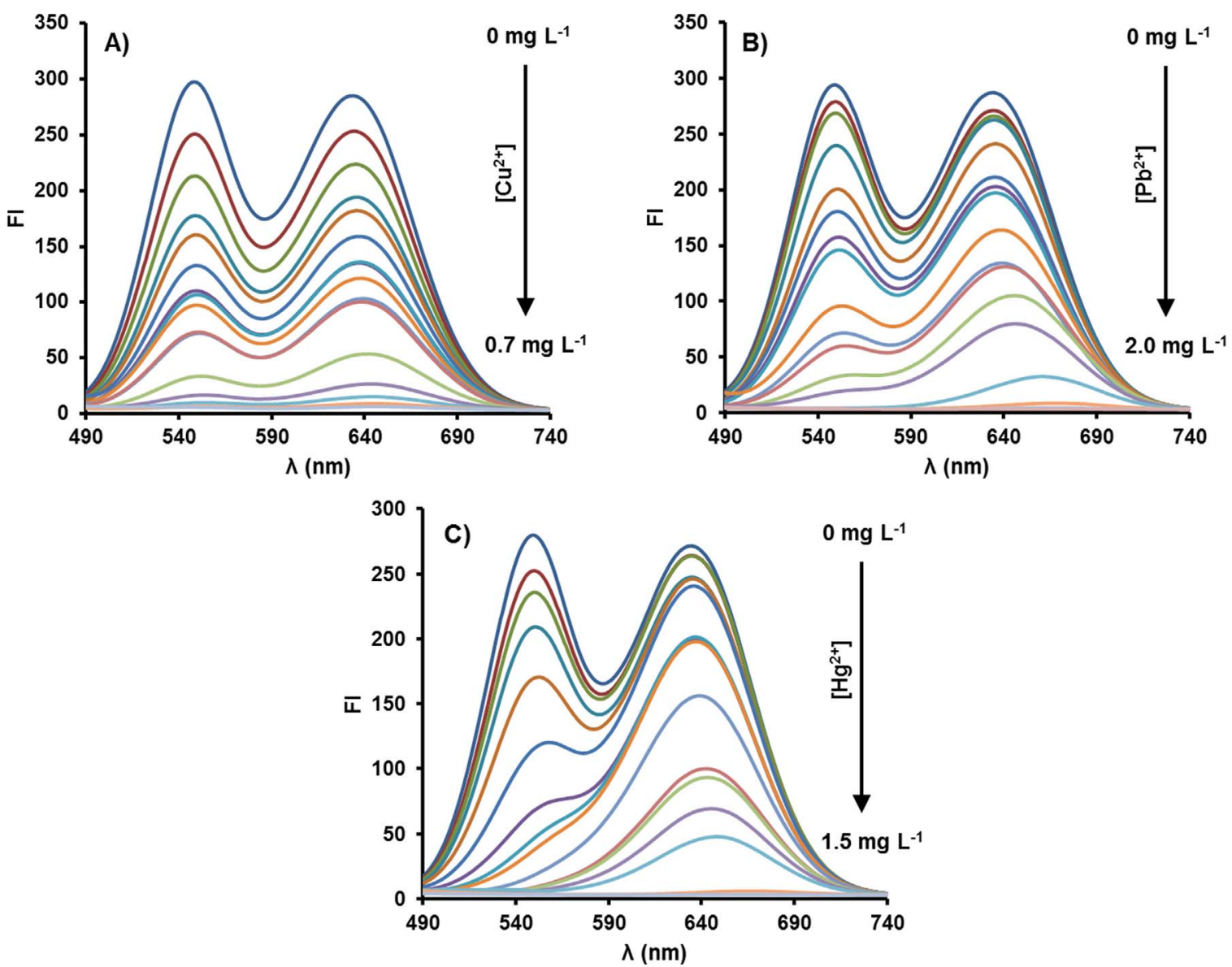

Fig. 3. Photoluminescence emission spectra of 549/634 nm MPA-CdTe QDs fluorometric probe in the presence of A) $\mathrm{Cu}(\mathrm{II})$, B) $\mathrm{Pb}(\mathrm{II})$ and C) $\mathrm{Hg}(\mathrm{II})$ at different concentrations.

sized QDs, the fluorometric response was based on the PL inhibition of both 549 and $634 \mathrm{~nm}$ emission bands. Therefore, the application of the Stern-Volmer equation to describe the PL quenching at both wavelengths was not adequate. For this reason, a chemometric approach consisting on a PLS-1 algorithm allowing the correlation between the obtained fluorometric response (X data) and the quencher concentration ( $\mathrm{Y}$ data) using the whole emission spectra, was developed and assessed for each of the individual metal ions. The obtained results confirmed that it was possible to establish a linear relationship between the quencher concentrations and the fluorometric response of the nanohybrid system, which are depicted in Table 3 and Fig. 4. For $\mathrm{Cu}(\mathrm{II})$ concentrations up to $0.15 \mathrm{mg} \mathrm{L}^{-1}$, a linear response was obtained with a $\mathrm{R}_{\mathrm{CV}}^{2}$ and a RMSECV of 0.98 and $0.006 \mathrm{mg} \mathrm{L}^{-1}$, respectively. In the case of $\mathrm{Pb}(\mathrm{II})$ and $\mathrm{Hg}(\mathrm{II})$ ions, a linear response was observed for 
Table 3

PLS model results for each analyte.

\begin{tabular}{llll}
\hline & $\mathrm{Cu}(\mathrm{II})$ & $\mathrm{Pb}(\mathrm{II})$ & $\mathrm{Hg}(\mathrm{II})$ \\
\hline Range $\left(\mathrm{mg} \mathrm{L}^{-1}\right)$ & $0-0.15$ & $0-1.25$ & $0-1.0$ \\
$\mathrm{LV}$ & 2 & 2 & 2 \\
$\mathrm{RMSECV}\left(\mathrm{mg} \mathrm{L}^{-1}\right)$ & 0.006 & 0.05 & 0.05 \\
$\mathrm{R}_{\mathrm{CV}}^{2}$ & 0.98 & 0.98 & 0.97 \\
\hline
\end{tabular}

concentrations of up to 1.25 and $1.0 \mathrm{mg} \mathrm{L}^{-1}$, respectively. The obtained $\mathrm{R}^{2} \mathrm{CV}$ and a RMSECV values were 0.98 and $0.05 \mathrm{mg} \mathrm{L}^{-1}$, for $\mathrm{Pb}$ (II) and 0.97 and $0.05 \mathrm{mg} \mathrm{L}^{-1}$, for the $\mathrm{Hg}(\mathrm{II})$ ions.

The possibility of detecting and quantifying $\mathrm{Cu}(\mathrm{II}), \mathrm{Pb}(\mathrm{II})$ and $\mathrm{Hg}$ (II) ions in binary and/or ternary mixtures relies in the specific features of the fluorometric response of each analyte. Additionally, the obtained results allowed setting the concentration ranges of each of the analytes for the following assays involving the interaction of the nanohybrid probe with a mixture of two and three of the ions under study.

\subsection{Interaction between the 549/634 nm MPA-CdTe QDs}

fluorometric probe and a mixture of two metal ions namely, $\mathrm{Hg}(\mathrm{II})-$ $\mathrm{Pb}(I I), \mathrm{Hg}(I I)-\mathrm{Cu}(\mathrm{II})$ and $\mathrm{Pb}(\mathrm{II})-\mathrm{Cu}(\mathrm{II})$

Since the previous results showed that different metals ions could produce distinct patterns on the PL quenching of the nanohybrid probe, the subsequent assays were aimed at investigating the possibility of discriminating distinct ions in a binary mixture by using the fluorometric response in combination with chemometrics methods. Thus, a mixture experimental design was used to obtain 39 samples for the calibration set at 6 concentration levels of each ion in a binary mixture. The concentration ranges used in the experimental design
Table 4

PLS model results for each analyte in the three mixtures containing two analytes.

\begin{tabular}{|c|c|c|c|}
\hline & $\mathrm{Hg}(\mathrm{II})-\mathrm{Pb}(\mathrm{II})$ & $\mathrm{Hg}$ (II)-Cu (II) & $\mathrm{Pb}$ (II)-Cu (II) \\
\hline \multirow[t]{2}{*}{ Range $\left(\mathrm{mg} \mathrm{L}^{-1}\right)$} & $0.1-0.4 \mathrm{Hg}(\mathrm{II})$ & $0.1-0.4 \mathrm{Hg}(\mathrm{II})$ & $0.05-0.6 \mathrm{~Pb}(\mathrm{II})$ \\
\hline & $0.05-0.6 \mathrm{~Pb}(\mathrm{II})$ & $0.01-0.08 \mathrm{Cu}(\mathrm{II})$ & $0.01-0.08 \mathrm{Cu}(\mathrm{II})$ \\
\hline \multirow[t]{2}{*}{ Pre-processing } & $\log 10$ mncn $\mathrm{Hg}(\mathrm{II})$ & mncn for $\mathrm{Hg}$ (II) & mncn for $\mathrm{Pb}(\mathrm{II})$ \\
\hline & mncn for $\mathrm{Pb}(\mathrm{II})$ & mncn for $\mathrm{Cu}$ (II) & mncn for $\mathrm{Cu}$ (II) \\
\hline \multirow[t]{2}{*}{ LV } & 5 for $\mathrm{Hg}(\mathrm{II})$ & 2 for $\mathrm{Hg}(\mathrm{II})$ & 4 for $\mathrm{Pb}(\mathrm{II})$ \\
\hline & 4 for $\mathrm{Pb}(\mathrm{II})$ & 2 for $\mathrm{Cu}(\mathrm{II})$ & 4 for $\mathrm{Cu}$ (II) \\
\hline \multirow[t]{2}{*}{ RMSECV $\left(\mathrm{mg} \mathrm{L}^{-1}\right)$} & 0.08 for $\mathrm{Pb}(\mathrm{II})$ & 0.04 for $\mathrm{Hg}(\mathrm{II})$ & 0.06 for $\mathrm{Pb}(\mathrm{II})$ \\
\hline & 0.06 for $\mathrm{Hg}$ (II) & 0.01 for $\mathrm{Cu}(\mathrm{II})$ & 0.01 for $\mathrm{Cu}(\mathrm{II})$ \\
\hline \multirow[t]{2}{*}{$\mathrm{R}_{\mathrm{CV}}^{2}$} & 0.81 for $\mathrm{Pb}(\mathrm{II})$ & 0.86 for $\mathrm{Hg}(\mathrm{II})$ & 0.89 for $\mathrm{Pb}(\mathrm{II})$ \\
\hline & 0.74 for $\mathrm{Hg}(\mathrm{II})$ & 0.81 for $\mathrm{Cu}(\mathrm{II})$ & 0.76 for $\mathrm{Cu}(\mathrm{II})$ \\
\hline
\end{tabular}

(Table 1) were as follows: $0.01-0.08,0.1-0.4$ and $0.05-0.6 \mathrm{mg} \mathrm{L}^{-1}$ for $\mathrm{Cu}(\mathrm{II}), \mathrm{Hg}(\mathrm{II})$ and $\mathrm{Pb}(\mathrm{II})$, respectively. As abovementioned, a PLS model was developed for each metal ion in each binary mixture, therefore a total of six PLS models were obtained. The obtained results (Table 4) revealed that it is possible to determine the concentration of each analyte in a binary mixture, since a good $\mathrm{R}_{\mathrm{CV}}^{2}$ was obtained for each ion. Moreover, the results pointed out that $\mathrm{Pb}$ (II) is the analyte that better correlates with the fluorometric response, followed by $\mathrm{Hg}(\mathrm{II})$ and $\mathrm{Cu}(\mathrm{II})$, respectively.

With the objective of understanding which regions in the fluorometric data (Supplementary material S1) are more important for the developed PLS models, the square of the regression coefficient vectors were depicted (Fig. 5). All these figures revealed that most of the fluorometric data were used in the PLS models. From Fig. 5(A) it can be seen that the most important regions for modelling the $\mathrm{Cu}$ (II) and $\mathrm{Hg}(\mathrm{II})$ concentrations were around 630 and $545 \mathrm{~nm}$, respectively. In other words, the obtained fluorometric response of the smallest QDs was more important for the $\mathrm{Hg}$ (II) PLS model while the largest
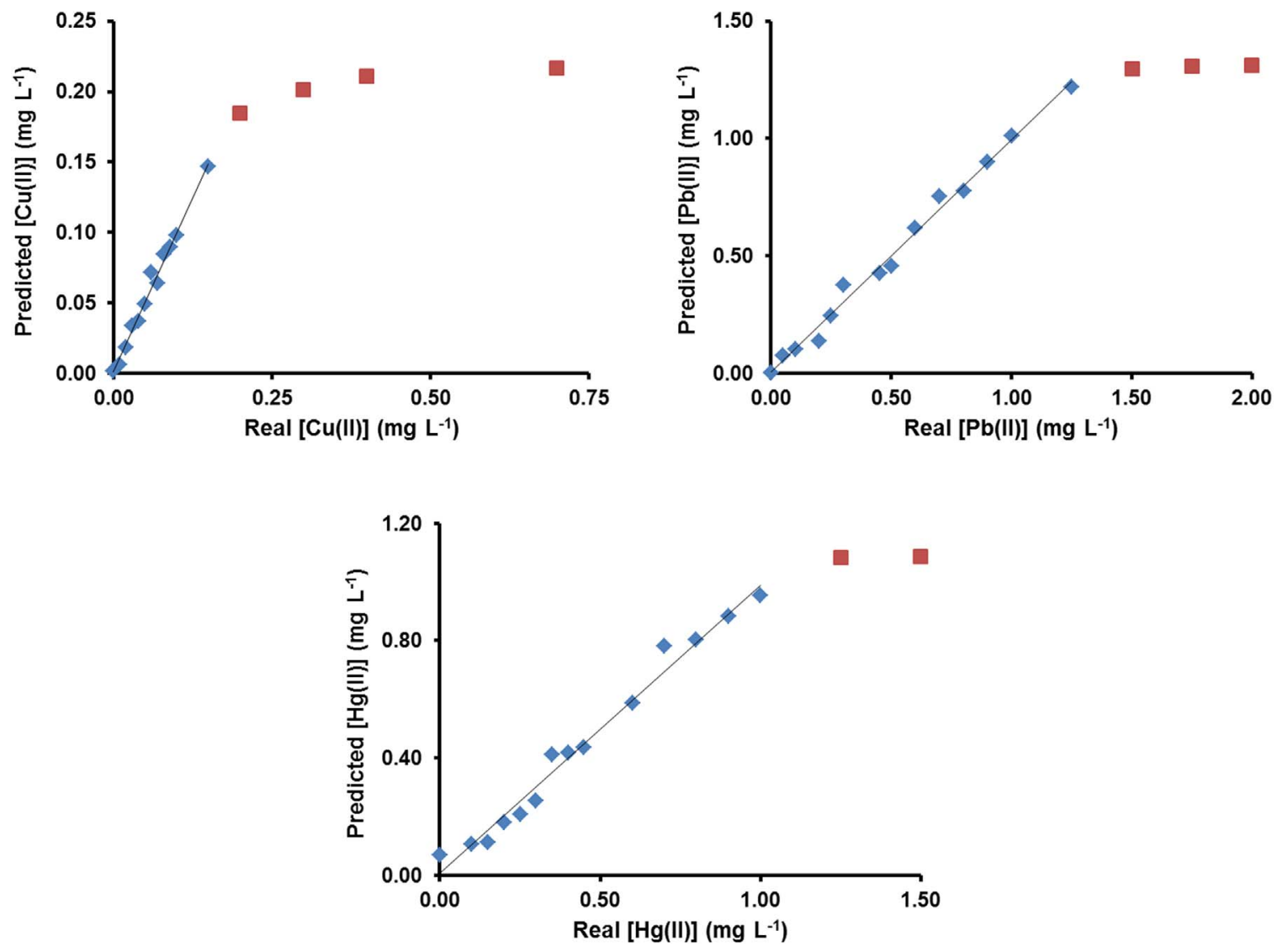

Fig. 4. Linear regression model by projecting the predicted and the real ion concentrations using the PLS 1 algorithm. 


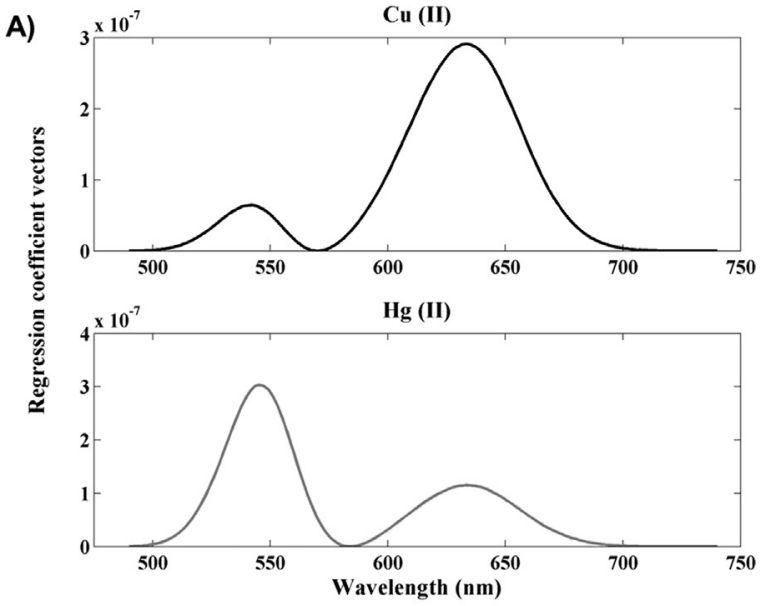

B)
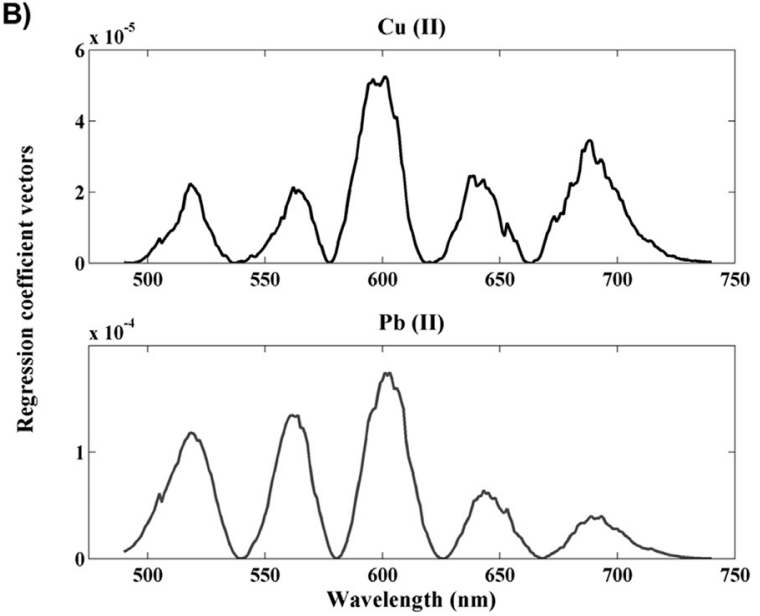

C)

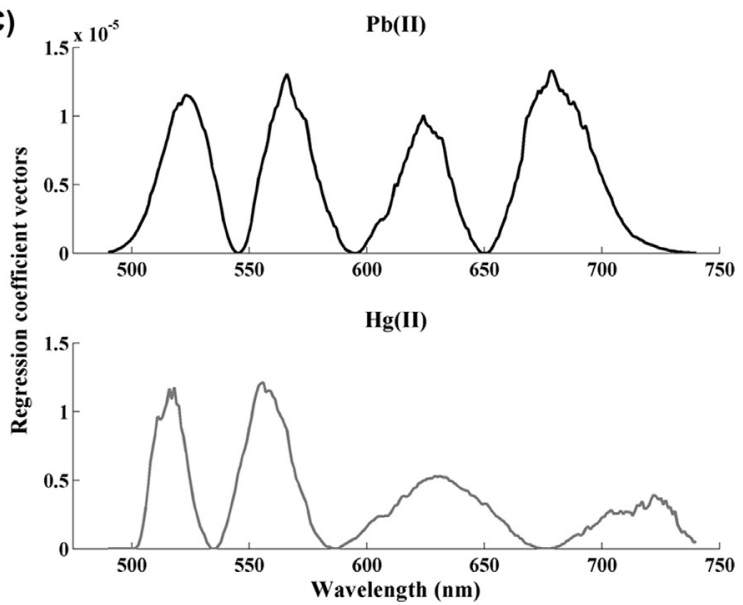

Fig. 5. Regression coefficient vectors of the PLS models built with (A) $\mathrm{Cu}(\mathrm{II})-\mathrm{Hg}(\mathrm{II})$; (B) $\mathrm{Cu}(\mathrm{II})-\mathrm{Pb}(\mathrm{II})$ and (C) $\mathrm{Pb}(\mathrm{II})-\mathrm{Hg}(\mathrm{II})$ mixtures fluorometric responses.

quantum dot fluorometric response was more important for the $\mathrm{Cu}(\mathrm{II})$ PLS model. This may justify why the $\mathrm{R}_{\mathrm{CV}}^{2}$ is good for both models. These results are in accordance with those obtained upon the interaction of the nanohybrid system probe with $\mathrm{Cu}(\mathrm{II})$ and $\mathrm{Hg}(\mathrm{II})$, individually. As can be seen in Fig. 3(C), $\mathrm{Hg}$ (II) ions showed a higher reactivity for the smaller QDs since a more noticeable PL quenching effect was observed on the $549 \mathrm{~nm}$ emission band for lower $\mathrm{Hg}$ (II) concentrations levels. On the other hand, the reactivity of $\mathrm{Cu}$ (II) ion with both sized QDs were similar (Fig. 3(A)).

Regarding Fig. 5(B), the regions around 520, 565, 600, 640 and $690 \mathrm{~nm}$ were the most important for modelling both $\mathrm{Cu}(\mathrm{II})$ and $\mathrm{Pb}(\mathrm{II})$.
There are no specific regions for each of these metal ions. The regression coefficient vectors obtained for the $\mathrm{Pb}(\mathrm{II})$ and $\mathrm{Hg}$ (II) PLS models (Fig. 5(C)) revealed that the most important regions were located around 525, 565, 625, 680 and 515, 555, 630, $725 \mathrm{~nm}$. Thus, the fluorometric data included in each PLS models were slightly different.

These assays allowed concluding that the combination of the multiple responses in a unique multi-QDs analytical signal can be useful to discriminate distinct analytes in a particular sample composition which affords enhanced selectivity in chemical analysis.

\subsection{Interaction between the 549/634 nm MPA-CdTe QDs}

fluorometric probe and a mixture of three metal ions $\mathrm{Hg}(\mathrm{II})-\mathrm{Pb}(\mathrm{II})-$ $\mathrm{Cu}(\mathrm{II})$

Having proved the suitability of the developed approach for the discrimination of two distinct ions in a binary mixture, the following assays were intended to evaluate if three different ions could be discriminated and simultaneously determined in a ternary mixture. Therefore, a mixture experimental design involving a set of 67 calibration samples for 4 concentration levels of $\mathrm{Hg}(\mathrm{II}), \mathrm{Pb}(\mathrm{II})$ and $\mathrm{Cu}(\mathrm{II})$ was used to obtain the regression models. The concentration ranges were similar to those tested in the mixtures containing two analytes but using only four different values (Table 1). A total of three PLS models, one for each metal ion, were obtained. The obtained results are shown in Table 5 . A very good correlation was obtained for $\mathrm{Pb}$ (II) with a $\mathrm{R}_{\mathrm{CV}}^{2}$ of 0.87 and a good correlation for $\mathrm{Hg}(\mathrm{II})\left(\mathrm{R}_{\mathrm{CV}}^{2} 0.73\right)$. In the case of $\mathrm{Cu}(\mathrm{II})$, the PLS model results revealed that this analyte can be detected in a mixture, however its quantification with accuracy is not feasible $\left(\mathrm{R}^{2} \mathrm{CV}\right.$ of 0.51$)$. An interesting possibility to solve this problem and guarantee the accurate discrimination of all metals could contemplate the inclusion on the fluorometric probe of a third QDs, with a dissimilar size and emitting at an alternative and complementary wavelength. This way, and assuming that this third QDs would have its specific reactivity towards the three metal ions, it would be possible to gather additional information that would facilitate sample resolution.

The square of the regression coefficient vectors obtained for each PLS model in this mixture were plotted (Fig. 6) with the objective of obtaining a better perspective on which wavelengths have a higher contribution. The wavelengths with the higher contribution for each PLS model were: 500, 515 and 590 for $\mathrm{Cu}(\mathrm{II}), 510,540$ and 610 for $\mathrm{Hg}$ (II) and 595, 620 and 660 for $\mathrm{Pb}(\mathrm{II})$. With the exception of the last wavelength region used for the $\mathrm{Pb}(\mathrm{II})$ PLS model, the other wavelengths regions with important contributions for each PLS model are very similar between them. This may justify why the obtained $\mathrm{R}_{\mathrm{CV}}^{2}$ values were lower for this three ions mixture than in the two ions mixtures. This multivariate approach showed some difficulties to separate the fluorometric response (Supplementary material S2) of each metal ion in the mixture, namely for $\mathrm{Cu}(\mathrm{II})$. However, the obtained results revealed that it is possible to build predictive models to estimate the concentrations of $\mathrm{Pb}$ (II) and $\mathrm{Hg}$ (II) with an acceptable accuracy in a ternary mixture.

The interaction of $\mathrm{Pb}(\mathrm{II})$ and $\mathrm{Hg}(\mathrm{II})$ with the nanohybrid system

Table 5

PLS model results for each analyte in the mixture containing three analytes.

\begin{tabular}{|c|c|c|c|}
\hline & \multicolumn{3}{|c|}{ Hg (II)-Pb (II)-Cu (II) } \\
\hline & Hg (II) & $\mathrm{Pb}(\mathrm{II})$ & $\mathrm{Cu}$ (II) \\
\hline Range $\left(\mathrm{mg} \mathrm{L}^{-1}\right)$ & $0.1-0.4$ & $0.05-0.6$ & $0.01-0.08$ \\
\hline Pre-processing & Log 10 and mncn & Mean center & Log 10 and mncn \\
\hline LV & 4 & 6 & 4 \\
\hline RMSECV & $0.06 \mathrm{mg} \mathrm{L}^{-1}$ & $0.08 \mathrm{mg} \mathrm{L}^{-1}$ & $0.02 \mathrm{mg} \mathrm{L}^{-1}$ \\
\hline $\mathrm{R}_{\mathrm{CV}}^{2}$ & 0.73 & 0.87 & 0.51 \\
\hline
\end{tabular}




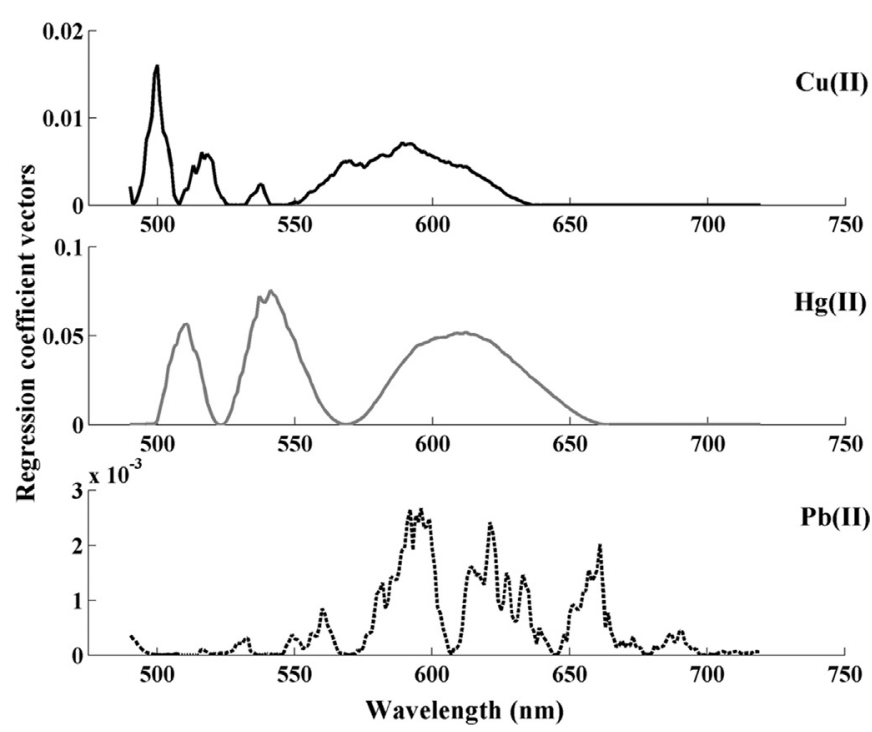

Fig. 6. Regression coefficient vectors of the PLS models built with the $\mathrm{Hg}$ (II)-Pb(II)$\mathrm{Cu}(\mathrm{II})$ mixture fluorometric response.

revealed some specificity in the fluorometric response which was not observed in the interaction with $\mathrm{Cu}(\mathrm{II})$ ions. Namely, both $\mathrm{Pb}(\mathrm{II})$ and $\mathrm{Hg}$ (II) showed a higher reactivity with the smaller QDs wherein a more pronounced PL inhibition was observed in the $549 \mathrm{~nm}$ emission band. Moreover, a marked red shift of the $634 \mathrm{~nm}$ emission band was verified. This specificity in the fluorometric response can justify the achievement of better PLS models. For example, the regression coefficient vectors of $\mathrm{Pb}(\mathrm{II})$ revealed a higher contribution in the $660 \mathrm{~nm}$ region which may be connected with the observed red shift of the $634 \mathrm{~nm}$ emission band. This could justify the better PLS model results obtained for $\mathrm{Pb}(\mathrm{II})$, and consequently its quantification with a higher accuracy. Concerning $\mathrm{Hg}(\mathrm{II})$, some particularities can be highlighted as well. The regression coefficient vector of $\mathrm{Hg}$ (II) demonstrated a relevant contribution in the region around $540 \mathrm{~nm}$ which can be ascribed to the higher reactivity of these metal ion to the smaller QD in the nanohybrid system probe. This specific feature can explain the good PLS model results obtained for $\mathrm{Hg}$ (II). Regarding $\mathrm{Cu}(\mathrm{II})$, as there was no relevant feature observed in the respective emission spectra and the most important wavelength regions were very similar to those of the other two metal ions, this could justify why the PLS model results for $\mathrm{Cu}(\mathrm{II})$ were not so good.

\section{Conclusion}

This work demonstrated that the combination of the multiple responses of a fluorometric probe comprising two different sized MPA-CdTe QDs can be useful to pattern-based discrimination of different metal ions in a given mixture. Indeed, the application of multivariate calibration methods for the detection and quantification of distinct metal ions in a binary mixture based on the whole fluorescence response of a nanohybrid system was successfully achieved. In the case of the ternary mixtures, $\mathrm{Pb}(\mathrm{II})$ and $\mathrm{Hg}$ (II) can be detected and quantified with a good accuracy while $\mathrm{Cu}(\mathrm{II})$ ions can only be detected in the ternary mixture being its quantification unfeasible.

Although the results were extremely encouraging, they were not fully satisfactory in particular with regard to the accurate quantification of all three distinct metal ions in ternary mixtures. However, it could be reasonably anticipated that a combination of three QDs of different size and reactivity could provide the additional data required to fulfill this task.

It is important to refer that this study was not intended to replace any analytical methods already proposed to determine these analytes. However, the obtained results provide new insights on the potential application of QDs as fluorometric probes and on the strategies that could be implemented to circumvent the problems of selectivity associated with their use in chemical analysis.

Further studies are needed to better understand the interaction of more metal ions and other quantum dot systems, if possible using more complex QDs mixtures.

\section{Acknowledgments}

Dayana B. Bittar is grateful to CAPES for the scholarship (PDSE no. 99999.000651/2015-00). David S.M. Ribeiro and Ricardo N.M.J. Pascoa thank FCT (Fundação para a Ciência e Tecnologia) and POPH (Programa Operacional Potencial Humano) for the Post-Doc grants ref. SFRH/BPD/104638/2014 and SFRH/BPD/81384/2011, respectively. S. Sofia M. Rodrigues thanks the financial support from Operação NORTE-01-0145-FEDER-000011 - Qualidade e Segurança Alimentar-uma abordagem (nano) tecnológica. José X. Soares thanks FCT (Fundação para a Ciência e Tecnologia) and POPH (Programa Operacional Potencial Humano) for his Ph.D. Grant Ref. SFRH/BD/ 98105/2013, and also the Biotech Health Programme (Doctoral Programme on Cellular and Molecular Biotechnology Applied to Health Sciences), Reference PD/00016/2012. This work received financial support from the European Union (FEDER funds POCI/01/ 0145/ FEDER/007265) and National Funds (FCT/MEC, Fundação para a Ciência e Tecnologia and Ministério da Educação e Ciência) under the Partnership Agreement PT2020UID/QUI/50006/2013.

\section{Appendix A. Supporting information}

Supplementary data associated with this article can be found in the online version at doi:10.1016/j.talanta.2017.06.071.

\section{References}

[1] W.R. Algar, A.J. Tavares, U.J. Krull, Beyond labels: a review of the application of quantum dots as integrated components of assays, bioprobes, and biosensors utilizing optical transduction, Anal. Chim. Acta 673 (2010) 1-25.

[2] C. Frigerio, D.S.M. Ribeiro, S.S.M. Rodrigues, V.L.R.G. Abreu, J.A.C. Barbosa, J.A.V. Prior, K.L. Marques, J.L.M. Santos, Application of quantum dots as analytical tools in automated chemical analysis: a review, Anal. Chim. Acta 735 (2012) 9-22.

[3] N. Gaponik, D.V. Talapin, A.L. Rogach, K. Hoppe, E.V. Shevchenko, A. Kornowski, A. Eychmüller, H. Weller, Thiol-capping of CdTe nanocrystals: an alternative to organometallic synthetic routes, J. Phys. Chem. B 106 (2002) 7177-7185.

[4] C. Frigerio, V.L.R.G. Abreu, J.L.M. Santos, Evaluation of acetylcysteine promoting effect on CdTe nanocrystals photoluminescence by using a multipumping flow system, Talanta 96 (2012) 55-61.

[5] A.S. Lima, S.S.M. Rodrigues, M.G.A. Korn, D.S.M. Ribeiro, J.L.M. Santos, L.S.G. Teixeira, Determination of copper in biodiesel samples using CdTe-GSH quantum dots as photoluminescence probes, Microchem. J. 117 (2014) 144-148.

[6] S.S.M. Rodrigues, A.S. Lima, L.S.G. Teixeira, M.G.A. Korn, J.L.M. Santos, Determination of iron in biodiesel based on fluorescence quenching of CdTe quantum dots, Fuel 117 (2014) 520-527.

[7] S.S.M. Rodrigues, Z. Oleksiak, D.S.M. Ribeiro, E. Pobozy, M. Trojanowicz, J.A.V. Prior, J.L.M. Santos, Selective determination of sulphide based on photoluminescence quenching of MPA-capped CdTe nanocrystals by exploiting a gasdiffusion multi-pumping flow method, Anal. Methods 6 (2014) 7956-7966.

[8] S.S.M. Rodrigues, D.S.M. Ribeiro, L. Molina-Garcia, A. Ruiz Medina, J.A.V. Prior, J.L.M. Santos, Fluorescence enhancement of CdTe MPA-capped quantum dots by glutathione for hydrogen peroxide determination, Talanta 122 (2014) 157-165.

[9] S.S.M. Rodrigues, D.R. Prieto, D.S.M. Ribeiro, E. Barrado, J.A.V. Prior, J.L.M. Santos, Competitive metal-ligand binding between CdTe quantum dots and EDTA for free $\mathrm{Ca}^{2+}$ determination, Talanta 134 (2015) 173-182.

[10] S.S.M. Rodrigues, D.S.M. Ribeiro, J.X. Soares, M.L.C. Passos, M.L.M.F.S. Saraiva, J.L.M. Santos, Application of nanocrystalline CdTe quantum dots in chemical analysis: implementation of chemo-sensing schemes based on analyte-triggered photoluminescence modulation, Coord. Chem. Rev. 330 (2017) 127-143.

[11] E.M. Nolan, S.J. Lippard, Tools and tactics for the optical detection of mercuric ion, Chem. Rev. 108 (2008) 3443-3480.

[12] G.-X. Liang, H.-Y. Liu, J.-R. Zhang, J.-J. Zhu, Ultrasensitive $\mathrm{Cu}^{2+}$ sensing by nearinfrared-emitting CdSeTe alloyed quantum dots, Talanta 80 (2010) 2172-2176.

[13] X. Wang, X. Guo, Ultrasensitive $\mathrm{Pb}^{2+}$ detection based on fluorescence resonance energy transfer (FRET) between quantum dots and gold nanoparticles, Analyst 134 (2009) 1348-1354.

[14] I. Costas-Mora, V. Romero, I. Lavilla, C. Bendicho, An overview of recent advances 
in the application of quantum dots as luminescent probes to inorganic-trace analysis, Trends Anal. Chem. 57 (2014) 64-72.

[15] P. Wu, T. Zhao, S. Wang, X. Hou, Semiconductor quantum dots-based metal ion probes, Nanoscale 6 (2014) 43-64.

[16] D.S.M. Ribeiro, G.C.S. de Souza, A. Melo, J.X. Soares, S.S.M. Rodrigues,

A.N. Araújo, M.C.B.S.M. Montenegro, J.L.M. Santos, Synthesis of distinctly thiolcapped CdTe quantum dots under microwave heating: multivariate optimization and characterization, J. Mater. Sci. 52 (2017) 3208-3224.

[17] T. Naes, T. Isaksson, T. Fearn, T. Davies, Interpreting PCR and PLS solutions, in: A
User-Friendly Guide to Multivariate Calibration and Classification, NIR Publications, Chischester, UK, 2004.

[18] P. Geladi, B.R. Kowalski, Partial least-squares regression: a tutorial, Anal. Chim. Acta 185 (1986) 1-17.

[19] W.W. Yu, L. Qu, W. Guo, X. Peng, Experimental determination of the extinction coefficient of CdTe, CdSe, and CdS nanocrystals, Chem. Mater. 15 (2003) 2854-2860.

[20] W. Zhong, C. Zhang, Q. Gao, H. Li, Highly sensitive detection of lead(II) ion using multicolor CdTe quantum dots, Microchim. Acta 176 (2012) 101-107. 